\author{
Adson Cristiano Bozzi Ramatis Lima \\ Arquiteto e Urbanista (CAU/UFPB), professor não-titular da \\ Universidade Estadual de Maringá, Universidade Estadual \\ de Maringá, Departamento de Arquitetura e Urbanismo, \\ Avenida Colombo, Zona 7, CEP 87030-130, Maringá, PR, Brasil, \\ (44) 268-8854, adson.bozzi.lima@gmail.com
}

\begin{abstract}
Resumo
O filósofo francês Jean-Paul Sartre possuia uma relação de grande afetividade com a Itália e as suas cidades. E, sobre esta relação, deixou um grande testemunho: o livro inacabado e publicado postumamente de título La reine Albermale ou le dernier touriste. Com este texto como objeto de estudo, este artigo tem três objetivos: expor a relação de Sartre com as cidades italianas e a sua arquitetura; mostrar como o turismo de massa pode ser compreendido de maneira pejorativa por intelectuais europeus e ser diretamente relacionado aos norte-americanos; e, finalmente, expor a importância e a fortuna crítica da chamada narrativa de viagem.
\end{abstract}

Palavras-chave: Jean-Paul Sartre, turismo, Itália.

á tivemos a oportunidade de escrever e um publicar dois estudos sobre as reflexões que as cidades norte-americanas haviam despertado no filósofo francês Jean-Paul Sartre, e, desta vez, abordaremos as suas impressões sobre as cidades de um país que ele jamais deixou de amar: a Itália. Veremos que, apesar de as cidades e a sua arquitetura nunca tenham tido um papel determinante em seus escritos, estas não foram, todavia, sem importância na sua obra. Contudo, poder-se-ia argumentar que, face a sua colossal obra bibliográfica, de caráter principalmente político, filosófico e literário, a cidade foi apenas um tema marginal; mas, neste caso como em muitos outros, seria interessante lembrar que as margens, com as sua dobras e interstícios, também são portadoras de sentido... Ora, não se ama ou se admira uma nação ou uma cultura sem passar pelos seus vestígios materiais, e, como sabemos, a cidade e a sua arquitetura costumam ser a visibilidade mais espetacular desta mesma matéria. E, se ao contrário de Henri Lefebvre o nosso autor jamais tenha feito do urbano um tema de reflexão filosófica, postulamos a tese de que é possível depreender de alguns dos seus escritos um pensamento sobre a cidade - é o caso dos textos intitulados Villes d'Amérique e New York ville coloniale, já estudados por nós.

E, em relação ao sentimento devotado por Sartre às cidades italianas - o nosso presente objetivo - contase com um precioso documento: o livro não finalizado e publicado postumamente pela herdeira do seu espólio, a sua filha adotiva Arlette Elkaïm-Sartre, que tem como título La reine Albermale ou le dernier touriste. Ora, assim como os dois textos aludidos acima, trata-se de um escrito no qual a arquitetura e as cidades ocupam um espaço nada desprezível. Feitas estas consideração iniciais, é mister dar alguma notícia sobre a sua trama; este volume narra, entre outras ações, as peripécias de um turista estrangeiro na Itália, e é, como o leitor já terá pressentido, de caráter autobiográfico. Como já foi dito acima, Sartre nutria uma afeição profunda por este país, e servindo-nos desta narrativa, poderemos lançar luz sobre duas questões que julgamos pertinentes e mesmo fundamentais: o conhecimento teórico que o filósofo francês possuía sobre arquitetura e, em especial, sobre a arquitetura clássica italiana -, e a relação de um viajante com o próprio ato de viajar que se mescla com o ato de narrar a viagem. 
1 Uma breve viagem pela etimologia deste termo nos exporá a sua riqueza e a sua diversidade de sentidos implícitos: "A etimologia do verbo 'viajar' mostra bem uma evolução singular e concomitante com a história das mentalidades. Ele aparece, segundo os etimologistas, por volta de 1430, e o de viajante por volta de 1470 . Estes dois termos são derivados da palavra viagem, cujo sentido primeiro é em latim viaticum, que significa via, estrada, caminho. Viaticum designava "um caminho a percorrer" no latim da Gália. Na Idade Média, tinha a dupla significação de peregrinação, périgrinus, peregrinatio ascetica e de cruzada. [...] Não foi senão por volta do século XV que ele tomará a sua forma moderna, ligado notadamente ao desenvolvimento do capitalismo" (Fernandez, 2001, p. 10). Tradução nossa do Francês para o Português. No original lê-se: "L'étymologie du verbe "voyager" rend bien compte d'une évolution singulière et concomitante avec I'histoire des mentalités. Il apparaît selon les étymologistes vers 1430 et celui de voyageur vers 1470. Ces deux mots sont dérivés du mot voyage dont le sens premier est en latin viaticum qui signifie voie, route, chemin. Viaticum désignait un "chemin à parcourir"dans le latin de la Gaule. Au Moyen Age, le voyage avait une double signification à la fois celle de pélerinage, périgrinus, peregrinatio ascetica et celle de croisade. [...] Ce n'est que vers la fin du XVe siècle qu'il prendra sa forme moderne, lié notamment à l'essor du capitalisme européen."

2 Retiramos esta citação do livro A volta da prisão (ver referências), que é uma compilação de narrativas de viagem. Em nota, o editor adverte: "A citação exata é a seguinte: 'Quem seria insensato a ponto de morrer sem ter feito ao menos a volta da sua prisão?'" (A obra em negro: A Estrada, Nova Fronteira, 1981).

3 Há o sentido, por assim dizer, prático, da escrita - finalidades contábeis, laudatórias etc -, mas as razões pelas quais um indivíduo específico toma adecisão de registrar ...continua na próxima página
Neste sentido, teremos a oportunidade de observar a reação mal-humorada - para dizer o mínimo... que Sartre emprestou a sua personagem quando se tratava de escrever sobre turismo e turistas. Isto é significativo e interessante porque a própria personagem - criação de um autor que era, ele mesmo, um aficionado por viagens - é nomeado apenas como o "turista". Aquele que vislumbrou com muito interesse a possibilidade de viajar pelos Estados Unidos da América nos anos de 1945 e 1946, e que se apaixonou pelas suas cidades e por uma certa francesa de New-York de nome Dolorès Vanetti, teria, naquele momento, desdenhado as experiências viáticas? E o "turista" do livro seria uma espécie de alter ego de Sartre, assim como, segundo a maioria dos críticos, o seria Roquentin? Neste sentido, uma náusea por viagens se anunciaria? Teremos a oportunidade de responder a esta questão nas páginas que seguem.

No entanto, antes de narrarmos a experiência italiana de Sartre, tal como esta pode ser apreendida no supracitado livro, o leitor nos permitirá um capítulo introdutório - não muito breve, confessamo-lo - que apresenta como tema, justamente, as viagens e a sua relação profunda com a escritura, posto que aquele que empreende as viagens, freqüentemente, as narra. Esta questão não é secundária e nem pode ser compreendida como uma digressão na economia do nosso texto, uma vez que pretendemos estudar, justamente, uma narrativa de viagem. Após isto, apresentaremos ao leitor, então - e finalmente -, as cidades italianas sob o olhar atento de Jean-Paul Sartre.

\section{Sobre as viagens}

Como se trata de um capítulo introdutório, é importante buscarmos, se não a exaustão do tema, ao menos uma tentativa de genealogia. Assim, se compreendermos o termo "viagem" na sua acepção mais simples, isto é, como um deslocamento em uma certa extensão, veremos que esta atividade está íntima e fundamentalmente ligada a própria história do gênero humano ${ }^{1}$. Seja movido por interesses religiosos, políticos, militares ou comerciais, o homem tem uma longa tradição peregrina - pensemos, a este respeito, nos grandes viajantes: Ulisses e o desejo de retorno a sua pátria, Alexandre e a conquista do mundo até então conhecido pelos ocidentais, Marco Pólo embrenhando-se na China, Paracelso,
Jean de Léry... Os exemplos, como vemos, tanto os históricos quanto os legendários, são abundantes. Zenão, como personagem ficcional da escritora belga Marguerite Yourcenar - ela mesmo uma grande viajante - chega ao ponto de exclamar: "Quem desejaria morrer sem ter ao menos feito a volta [tour] na sua prisão?"2 Esta pequena frase tem o mérito de lembrar-nos que o mundo já era explorado e conhecido muito antes da criação do turismo de massa, e que a prática da viagem é uma prática de todos os tempos

Mas há uma outra dimensão da viagem que ultrapassa o deslocamento espaço-temporal, uma dimensão que nos alça ao coletivo - ora, sabemos das viagens pelo seu registro, isto é, pela sua escritura... Citamos acima alguns viajantes, mas faltaria citar os seus autores: Homero, Plutarco, e, novamente, Marco Pólo e Jean de Léry. Parece-nos que a atividade da viagem está intrinsecamente associada ao ato de narrá-la, e, assim como se viaja pelos mais diversos motivos, o viajante narra motivado pelas mais distintas razões ${ }^{3}$. No entanto, é importante salientar que desde a sua criação há um caráter na escritura que a atravessa e a marca: a permanência - ora, não é este o sentido do adágio latino já bastante vulgar verba volant scripta manent? Ou seja, se o legendário escritor Homero grafava mitos já existentes e se Jean de Léry descrevia a França Antártica, o que ambos fizeram perdurou no seu caráter de registro. Neste sentido, há, por um lado, o deslocamento da viagem, e, por outro lado, a sua narrativa - viagens e livros parecem apenas inseparáveis aparências de um mesmo objeto ${ }^{4}$. E se novamente recorrermos a Yourcenar, veremos que esta nossa última asserção não é inverossímil: "Identificando com razão o estudo e a viagem, ele [Zenão] teve por momentos a impressão de caminhar sobre o mundo como sobre um livro aberto" (1992, p. 119). A escritora belga se refere à dimensão espacial da escrita: se pudemos fazer as asserções no caput deste texto é porque há os registros, as evidências materiais dos deslocamentos. Podemos citar, como ilustração do que foi escrito acima, um dos verbetes para o termo "viagem" do Dictionnaire Universel de Antoine Furetière:

Transporte que uma pessoa faz a lugares distantes. Viaja-se por curiosidade ou para ver coisas raras [...]. As viagens são importantes para a juventude aprender a viver no mundo. Imprimiram-se as grandes 
continuação da nota 3 ..

certos acontecimentos pela escrita são extremamente complexas e dificilmente discerníveis, e não são o objeto de nosso estudo.

4 Cito, a este respeito, a professora da Universidade francesa Aix-Marseille I, Sylvie Requemora: "No século XIV o gênero viático era destinado a uma minoria de humanistas e cosmógrafos, no século XVII as fronteiras entre letras eruditas e cultura geral se apagam" (2002, p. 249). Tradução nossa do Francês. No origainal lê-se: "Au XIVe siècle, le genre viatique est destiné à une minorité d'humanistes et de cosmographes, au XVIle les frontières entre lettres érudites et culture générale s'estompent." E, ainda sobre a relação entre viagem e escritura: "O gênero viático parece se tornar o concorrente da literatura de ficção. [...] Na medida em que o romance barroco cai em descrédito, e antes do nascimento do romance realista e psicológico, a narrativa de viagem vem ocupar um lugar vago. Seu caráter instrutivo faz dele uma obra digna de ser lida, e vice-versa, ela confere ao romance de viagem, gênero menor na época em que servia de fonte, como Polexandre de Gomberville, novas letras de nobreza lhe conferindo uma autenticidade de documento e uma forma de seriedade científica que a ficção isolada não pode atingir". Tradução nossa do Francês. No original lê-se: "Le genre viatique semble devenir le concurrent de la littérature de fiction. [...] À mesure que le roman baroque tombe en discrédit, et avant la naissance du roman réaliste et psychologique, le récit de voyage vient occuper une place vacante. Son caractere instructif fait de lui une oeuvre digne d'être lue, et vice versa, il donne au roman de voyage, genre mineur à l'époque qui s'en sert comme source, comme Polexandre de Gomberville, de nouvelles lettres de noblesse en lui conférant une authenticité documentaire et une forme de sérieux scientifique que la fiction seule ne peut pas atteindre" (Requemora, 2002, p. 251)

5Tradução nossa do Francês para o Português. No original lê-se: "Transport qu'on ..continua na próxima página viagens em seis volumes, assim como as viagens de Cristóvão Colombo, de François Drac, de Thévenot, de Herbert, \&c. [...] Tavenier fez seis vezes a viagem das Índias para fazer comércio. Relações de viagens impressas. Nada é mais instrutivo que a leitura das viagens. Chama-se viagem de longa duração aquela que se faz em navios que demoram a voltar, como a viagem das Índias, da América. Para serem chamadas assim é necessário pelo menos mil ou 1.300 léguas [lieues no original, equivalendo a 5.067,4 quilômetros na distância colocada pelo autor ${ }^{5}$.

Mas se trata apenas de uma amostra, o dicionário de Furetière, publicado em 1690, estabelece vários sentidos para "viagem", tanto um simples deslocamento na própria cidade como uma possível metáfora para a morte, "uma grande viagem, uma viagem sem retorno". O que nos interessa neste extrato, no entanto, é algo mais restrito, a relação bastante próxima entre a atividade de viajar e o ato de narrar. Viagem é o ato de deslocamento, e, igualmente, o seu relato, a viagem impressa. Um exemplo que talvez torne a nossa exposição mais clara é o verbete de Furetière para "viajante", que o define tanto como aquele que faz viagens quanto aquele que delas faz as relações, isto é, quem as narra. Como se pode observar, quem diz viajante diz escritor.

Chamamos atenção no extrato citado do verbete, ainda, para a seguinte questão, a saber, o caráter pedagógico ou de "iniciação" do ato de viajar: este ato educa a juventude e a leitura da sua narrativa é instrutiva ${ }^{6}$. Neste caso, pode-se perguntar por que um ato que indica, na sua acepção mais simples, um mero deslocamento no espaço, teria tal dimensão. Ora, sabe-se que a viagem é o ato, por excelência, do encontro com o "outro", com aquilo que é julgado ou percebido como o "diferente", ou, em termos mais simples, com aquilo que não se é ${ }^{7}$. O viajante descreve, compara, aproxima o que observa - as "coisas raras" aludidas pelo acadêmico francês -, tendo como referência a sua própria cultura, e é sempre importante acrescentar, aquilo que é considerado raro o é justamente por ser desconhecido. Naturalmente que se viaja com outros objetivos, inclusive aquele de rever o que já é de longa data conhecido, mas este tipo de viagem raramente inspira um relato, isto é, uma narrativa. Não haveria o espanto que é o motor que impulsiona o gênero viático ${ }^{8}$. Um bom exemplo destas nossas afirmações é Jean-Paul Sartre, que realizou duas viagens aos Estados Unidos da América, em 1945 e 1946, e apenas a primeira suscitou narrativas que podem ser consideradas viáticas.

Apenas para completar o quadro geral traçado a partir do verbete de Furétière, faz-se necessário afirmar que as viagens estiveram, durante um período relativamente longo, profundamente ligadas ao ato de se instruir: era o tempo do Grand Tour, que entre os séculos XVI e XVIII era responsável por finalizar a educação da nobreza européia. Como afirma Jean Boutier ${ }^{9}$, esta prática não era uniforme e até os itinerários e o calendário sofreram uma grande variação ao longo dos séculos nos quais foi praticada, mas uma mesma questão permaneceu inalterada durante todo este tempo: o Grand Tour não era uma viagem qualquer, e nem era uma viagem de recreio, trata-se de aprimorar, por meio de uma estadia em terras estrangeiras, a educação dos jovens aristocráticos, e, depois, da alta burguesia. Ora, se nem todas as viagens praticadas sob o signo do Grand Tour resultaram em "narrativas de viagem", é inegável, todavia, que a hipótese que postulamos acima, a saber, a relação íntima entre viagem e escritura, encontra nesta prática uma confirmação. Britânicos na França, Franceses na Alemanha, Alemães na Itália, houve um período em que as viagens, tanto aquelas que transcorriam no espaço mensurável quanto as que se davam a partir do espaço da escritura, eram sinônimo de experiência e de aprendizado.

Pensando-se sob este ponto de vista, isto é, viagens e escritura em uma dimensão transnacional, não causa espécie o fato de que as narrativas de viagem sejam um campo privilegiado da Literatura Comparada: se comparar é aproximar o desconhecido ao conhecido, esta é a própria operação tanto do viajante quanto do comparatista literário ${ }^{10}$. O viajante-escritor que retorna de um país estrangeiro é o intermediário cultural e o agente responsável por ampliar o conhecimento que uma certa sociedade possui sobre uma outra ${ }^{11}$. E este saber, é importante salientar, é tanto idiossincrático quanto coletivo: a Itália de Stendhal é certamente o fruto de uma experiência pessoal, mas que pode ser reconhecida por um grupo social que partilhe os seus valores culturais. No caput deste sub-capítulo havíamos aludido ao aedo Homero, lendário autor da llíada e da Odisséia, e é justamente pela escritura que certas cidades se tornam "míticas": Tróia, Roma, Florença, Veneza, 
continuação da nota 5 ...

fait de sa personne en des lieux esloignez. On fait voyage par curiosité pour voir des choses rares. [...]. Les voyages sont importantes pour la jeunesse apprendre a vivre dans le monde. On a imprimé les grands voyages en six volumes, comme aussi les voyages de Christophe Colomb, de François Drac, de Thévenot, de Herbert, \&c. Tavernier a fait six fois le voyage des Indes pour faire commerce. [...] II y a plus de 1300. Relations de voyages imprimées. Rien n'est plus instructif que la lecture des voyages. On appelle voyage de long cours, ceux qu'on fait des navires qui doivent longtemps à revenir, comme ceux des Indes, de I'Amérique. Pour les appeller ainsi, il faut qu'ils soient du moins de mille ou 1300 lieues." Disponível em: www.gallica.fr, acessado em 22 de setembro de 2008.

6 Sartre foi um grande viajante, e nele a perspectiva viática aproxima-se da escritura, como nos narra Simone de Beauvoir: "Ansiosos por viajar, gostávamos das reportagens. Tentamos imaginar Nova lorque por Paul Morand e a índia segundo L'Inde contre les Anglais [em Francês no original], de André Viollis. É através desta literatura que se conhece melhor um país estrangeiro; o que nos interessava era a URSS; líamos todos os jovens autores russos traduzidos para o Francês." In: Beauvoir, Simone de. A força da idade. Trad.: Sérgio Millet. Rio de Janeiro: Nova Fronteira, 1984, p. 50. A questão da relação próxima entre a viagem e a escritura está bem colocada por Beauvoir, nesta citação, todavia, um ponto se anuncia como inquietante: a URSS seria, então, o país o qual eles mais esperavam e mesmo ansiavam conhecer através de uma viagem? Mas... este país não deveria ser os Estados Unidos da América?! Ora, suspeitamos que os EUA poderiam ser as famosas "uvas verdes demais"... Neste ponto talvez tenhamos razão, posto que mais adiante a escritora francesa se entrega: "A América brilhava ao longe com mais brilho do que qualquer outro país, mas não esperávamos muito ter um dia os meios de por os pés naquela terra; ...continua na próxima página
Paris, e, mais recentemente, New York ${ }^{12}$. O viajanteescritor é um re-fundador de cidades.

$E$, se em muitos casos é a curiosidade em relação ao desconhecido que leva à viagem, é o "espanto" que funciona como o fator que impulsiona as descrições - o estrangeiro espanta-se, assusta-se, maravilha-se com o que encontra e vê: o "outro", que pode ser, aliás, "infernal". Mas como este "outro" é convocado no gênero viático? Sabe-se que a sua forma mais comum é o estereótipo: como só é possível apreender alguma coisa pelo que se é, os limites são, muitas vezes, restritos. E se pensarmos que muitas destas narrativas foram produzidas após uma viagem que pode ter sido breve, o estereótipo quase se impõe. É o que afirma Bernard Fernandez, ao se referir ao ato de se ver algo pela primeira vez:

Segundo ensinamento sempre atual, a tomada de consciência de um mundo radicalmente outro permanece um obstáculo maior. Como ver o que nunca se pensou? Ver não é reencontrar, pois o ato de ver é ele mesmo tomado em um esquema de representações mentais e culturais que nos impedem de descobrir o que se apresenta à vista. No índio do Novo Mundo Colombo via o Homem do Éden, o mito do bom selvagem, isto é, o nosso alter ego do Gênese. ${ }^{13}$

Lição valiosa esta... Os ameríndios vistos pela primeira vez pelos europeus tornaram-se os "bons selvagens" a assombrar o pensamento culto da época. Sabe-se que na cultura européia abundam representações mentais esquemáticas do pensamento da alteridade, e dito de uma maneira mais breve e incisiva, os tais estereótipos: ora, o que seriam as chinoiseries, japonnaiseries, indienneries e turqueries senão, justamente, estereótipos?... ${ }^{14}$ Não se pode esquecer que, em muitos casos, a banalidade é a companheira da curiosidade e ambas partem juntas na bagagem de muitos viajantes ${ }^{15}$. Ao escrever sobre viagens Marguerite Yourcenar observa que os soldados americanos que estiveram no Japão durante a Segunda Guerra Mundial pouco teriam aprendido sobre este país, e que os soldados ingleses e franceses em Dardanelos pouco teriam conhecido da Ásia; afirma, ainda, que os ocidentais nas cruzadas teriam trazido relíquias muitas vezes falsas dos lugares conquistados - e pilhados, como foi o caso de Constantinopla -, fato histórico que ela percebe quase como o anúncio das banais viagens de turismo dos tempos modernos (1992, p. 122).

Um outro topos de grande importância no gênero viático é o dépaysement que muitos viajantesescritores representam. O sentimento do lar deixado para trás aliado à visão da paisagem estrangeira causam este sentimento de nostalgia que tanto evoca a rememoração quanto por ela é provocada. Optamos por conservar a expressão na língua francesa e, por conseguinte, por não traduzi-la por termos como "mudança", "nostalgia" ou mesmo "saudades", porque nesta palavra está inscrito pays, cuja tradução por "país" não contempla todas as possibilidades e alcances do original. Ora, pays significa, certamente, país, mas também é sinônimo de região, vila, localidade e até mesmo - e é este sentido aquele que mais nos interessa - lugar de origem. ${ }^{16} \mathrm{O}$ dépaysement significa, e mesmo etimologicamente, estar fora do seu local de origem e todas as conseqüências que este fato acarreta: nostalgia, desorientação e estranheza. É mais uma figura estruturalmente ligada à história do gênero humano: os soldados de Alexandre, por acaso, não suplicaram por voltar a Macedônia? Mas estes homens tinham, ao menos, uma pátria a qual retornar, mas o que dizer da figura do judeu errante, este ser eternamente desenraizado?

Resta ainda mencionar os exilados de todos os tempos por razões políticas ou religiosas. O ostracismo no mundo grego era sempre uma punição a um cidadão que tivesse se tornado excessivamente popular e influente: era banido por dez anos, prazo longo o suficiente para que fosse neutralizado e esquecido ${ }^{17}$. Mas, é importante salientar, o banimento nem sempre é sinônimo de esquecimento: Napoleão isolado na ilha de Santa Helena foi uma imagem que muito seduziu os espíritos românticos do século XIX.

E há, ainda, figura do colono. A escritora Marguerite Duras conta que, tendo viajado à Indochina Francesa muito jovem, estava, assim como o seu irmão mais novo, perfeitamente ambientada ao local, ao ponto que tinham que lembrá-la de que ela era francesa - a sua mãe, no entanto, jamais se acostumou com os tristes trópicos do sudeste Asiático: "Ela tinha medo daquela estranheza, destes trópicos que ela descobriu tarde na sua vida." 18 E é justamente o medo daquilo que é percebido como estranho, isto é, como estrangeiro, que é a marca do sentimento 
continuação da nota 6 ... por enquanto, em todo caso estava fora de cogitação" (1984, p. 326)

7 Muitos autores perceberam esta dimensão da viagem, e a já citada Slyvie Requemora coloca a questão nos seguintes termos: "O 'imaginário da deambulação curiosa', para retormar a fórmula de Florence Dumora-Mabille, retirada das narrativas de viagem, é extraído da literatura de curiosidade, com freqüência julgada como uma literatura da vaidade pelos moralistas e pelos teólogos. No entanto, a curiosidade exótica tem virtudes morais, sociais e políticas: suscitando a exteriozação do sujeito que experimenta assim a alteridade e a sua própria diferença, ela é um meio paradoxal de soldar a identidade nacional através de uma espécie de 'exploração curiosa de um interior fora-do-sujeito'" Para ter acesso ao conhecimento de si, o viajante deve se deduzir do outro a partir de um suposto fundo de identidade da natureza humana." Tradução nossa do Francês para o Português. No original lê-se: "L'imaginaire de la déambulation curieuse', pour reprendre la formule de Florence Dumora-Mabille, issu des récits de voyage, sourd donc bien de la littérature de la curiosité, souvent jugée comme une littérature de la vanité par les moralistes et les théologiens. Pourtant, la curiosité exotique a des vertus morales, sociales et politiques : suscitant l'extériorisation du sujet qui expérimente ainsi l'altérité et sa propre différence, elle est un moyen paradoxal de souder l'identité nationale à travers une sorte $\mathrm{d}^{\prime \prime}$ exploration curieuse d'un hors-sujet intérieur'. Pour accéder à la connaissance de soi, le voyageur doit se déduire de l'autre à partir d'un fond d'identité supposée de la nature humaine" (Requemora, 2002, p. 264)

8Teremos a oportunidade de abordar a questão do "espanto" mais adiante.

9 Professor da EHESS e diretor do SHADY (Sociologie, histoire, antropologie des dynamiques culturelles).

10 Requemora lembra-nos que a comparação é um ..continua na próxima página de dépaysement que o viajante pode sentir. Em resumo, as narrativas de viagem como gênero literário apresentam estes topoi: o espanto, o encontro com a alteridade, o sentimento de dépaysement, o estrangeiro compreendido a partir de "esquema de representações mentais e culturais", isto é, o estereótipo, além do seu caráter eminentemente descritivo. Nas próximas páginas abordaremos um caso concreto, e que é o objeto deste artigo, a já citada narrativa que Jean-Paul Sartre escreveu sobre um turista estrangeiro na Itália. Mas a nossa exposição não estaria completa se não analisássemos um último tema de tanta importância para o gênero viático: o turismo e o chamado "turismo de massa" surgido, talvez, em meados do século XX. Ao tema, então.

Iniciaremos a nossa breve exposição com uma narrativa não menos breve: no ano de 1935 Sartre e Beauvoir, ainda intelectuais de poucos recursos pecuniários, fizeram uma viagem de "mochileiros" a Grécia, país europeu, então, extremamente pobre - e mais pobre ainda se pensarmo-lo desde a perspectiva dos países europeus hegemônicos da época, como a França, a Inglaterra e a Alemanha. E é Beauvoir que nos narra, a respeito desta viagem, um acontecimento de caráter anedótico: “De uma feita, quando passamos, crianças jogaram-nos pedras: 'Não gostam dos estrangeiros', pensamos placidamente" (1984, p. 302). Não deixa de ser curioso que, aquele que bem mais tarde receberia o epíteto de enfant terrible, já foi confundido por crianças com um turista banal, e, a este título, tratado com hostilidade pelos "locais". Ainda durante a viagem, no entanto, perceberam que não se tratava, propriamente, de uma rejeição pura e simples ao estrangeiro, mas de rejeição - que, neste caso, é o resultado de um ressentimento - a turistas de um país hegemônico por parte de uma população pobre. Convocamos este episódio em nossa escritura justamente porque este serve à perfeição para ilustrar a ambigüidade que cerca a figura do turista de massa: algumas vezes desprezado, outras tantas objeto de zombaria, esta figura parece carregar em si um certo estigma. Mas não foi sempre assim, e o turismo, e mesmo o turismo de massa, está, como toda viagem, imbricado com a escritura. Porém, neste caso, não se trata mais da chamada "alta literatura", como os textos já aludidos neste sub-capítulo, posto que agora nos referimos, como o leitor já terá percebido, aos famosos guias de viagem, estes "cicerones impressos"... Não se pode, evidentemente, comparar as crônicas de viajantes, que tinham a consciência de fazer literatura, com estas compilações de recomendações e de inventários de locais suscetíveis de despertar a curiosidade de algum turista, mas é lícito reconhecer que se trata, sempre, de viagens impressas.

Novamente, é mister constatar como a escritura - agora sob a forma dos guias de viagem - e o turismo estão intimamente ligados. E não estamos nos referindo apenas ao século passado, mas a um fenômeno que já era relativamente comum no século XIX. Martine Geronimi, professora da Universidade de Montreal, nos ensina que o primeiro guia de viagem sobre a América do Norte, por exemplo, foi publicado no longínquo ano de 1829, obra de G. Bourne e J. Smillie. E é certo que não se tratava de uma "invenção" ou de uma "aventura literária" destes escritores, mais uma vez, neste caso como em tantos outros, os autores respondem uma demanda social pré-existente. E não seria uma mera especulação se afirmássemos que, assim como há a "América" de Sartre e de Céline, exatamente pessoal a estes autores (mas que não é intransferível), há, em cada um destes guias, uma visão particular sobre uma dada região ou país, que é tanto idiossincrática quanto coletiva. Referindo-se ao já citado guia, Geronimi afirma: “Este guia exprime o código pitoresco inglês em vigor desde as viagens de Gilpin no século XVIII. Desde a primeira frase encontra-se o vocabulário caro aos românticos com o emprego do adjetivo 'pitoresco'." 19 A visão romântica de uma natureza entre o belo e o sublime não é, evidentemente, uma criação dos escritores de guias, mas estes últimos não são menos responsáveis pela sua propagação como imagem e fantasmagoria. Ora, assim como as imagens de um país ou a sua descrição literária preparam e moldam o que os viajantes verão tanto quanto aquilo que eles, inelutavelmente, ignorarão - o guia de viagem é uma espécie de antecipação ou de uma ante-visão da viagem. Ou, como preferiu Corbin, trata-se de uma "prescrição": "A propósito das praias armoricanas, o emprego do modo imperativo já não diz respeito apenas aos gestos a cumprir, mas também aos sentimentos 'românticos' a experimentar" (1989, p. 196). Neste sentido, um guia de viagem não seria apenas uma 
continuação da nota $10 \ldots$

procedimento clássico nas narrativas de viagem: "A comparação do desconhecido de além mar com o conhecido europeu é também um procedimento clássico. Frank Lestringant emprega a fórmula "mapa mundo em palimpsesto" para qualificar este fenômeno que consiste em comparar o desconhecido ao conhecido. O procedimento não concerne somente aos lugares e aos objetos, mas, igualmente, aos modos observados; ele é recorrente, e mostra os limites da abertura do viajante à alteridade e seu desejo de referencial. Este tópos revela quase um reflexo" Tradução nossa do Francês para o Português. No original lê-se: "La comparaison de l'inconnu outre-mer au connu européen est aussi un procede classique. Frank Lestringant emploie la formule "mappemonde en palimpseste" pour qualifier ce phénomène qui consiste à comparer l'inconnu au connu. Le procede ne concerne pas seulement les lieux et les objets, mais aussi les moeurs observées, il est très récurrent, il montre les limites de l'ouverture du voyageur à l'altérité et son besoin de référent. Ce topos relève quasiment du réflexe" (2002, p. 260).

11 Ver a este respeito: Brunel, p., Pichois, CL, Rousseau, A. M. Que é literatura comparada? São Paulo: Perspectiva, 1995. Recomendo, sobretudo, os sub-capítulos Os viajantes e $A$ influência das viagens.

12Paráfrase do seguinte extrato: "Ao redor de certas cidades se constituíram, como auras, verdadeiros mitos: Roma, Florença, Nápoles, Veneza, Weimar, paris, cujos elementos dinâmicos é interessante determinar". Em: Brunel, P., Pichois, CL, Rousseau, A. M. Que é literatura comparada? São Paulo: Perspectiva, 1995.

13 Tradução nosso do Francês para o Português. No original lê-se: "Deuxième enseignement toujours d'actualité, la prise de conscience d'un monde radicalement autre demeure un obstacle majeur. Comment voir ce que I'on a jamais pensé? Voir n'est pas rencontrer car l'acte de voir est lui même prit dans un ...continua na próxima página enumeração "seca" de monumentos e acidentes naturais a conhecer, mas haveria neles, explícita ou implicitamente, uma estética e uma ética do viajante: a maneira julgada correta em certas situações, os sentimentos que poderiam ser despertados diante de um acidente natural ou de uma obra bem julgada esteticamente. E talvez seja neste aspecto que resida a diferença fundamental entre os guias e as narrativas de viagem: tanto um como outro "educam", mas apenas os primeiros têm este caráter direto de prescrição, o que fazer e como fazê-lo diante do "outro".

Apenas para concluir este sub-capítulo, um breve comentário: em nosso texto os termos "turista" e "viajantes" se confundem um pouco, e seria necessário, neste momento, acrescentar uma distinção, ou, então, negá-la. Mas em relação ao nosso corpus esta distinção não faz muito sentido, mais importante seria diferenciar a experiência do "turista" e do "viajante" - e, sobretudo, do "viajante-escritor"- daquela do "turista de massa". Afinal, ninguém negaria que são experiências radicalmente diferentes... É neste sentido que o turista do final do século $X X$, sem glória nem prestígio, com os seus - muitas vezes, magros - recursos contabilizados dia a dia, parece ser uma espécie de filho bastardo do Grand Tour... No entanto, se nos ativermos a estas simples determinações, corremos o risco de sermos acusados de esnobismo, uma vez que ninguém afirmaria que as férias pagas e a facilidade de acesso à hospedagem e ao transporte não significaram uma melhoria para as classes populares ${ }^{20}$. A nossa distinção se dá em relação à experiência da viagem e a representação social que cada uma delas está investida, e não exatamente o "tipo" de viagem; ora, saber se se trata de um "viajante solitário" ou um "turista de pacote promocional" é menos importante do que o registro, por escrito, da viagem. Quando citamos o episódio de Sartre e Beauvoir na Grécia, queríamos justamente demonstrar como cada tipo de viagem implica possibilidades diferentes: em 1935 havia o Sartre "mochileiro", que chegou a enfrentar grandes privações e foi alvo de pedradas, houve o Sartre jornalista e intelectual prometteur das viagens aos Estados Unidos da América, e o Sartre jet-set das inúmeras viagens realizadas a partir dos anos 1950 - tratam-se de diferentes viagens com a experiência que cada uma delas implica.

\section{Sartre, narrador do último turista: Veneza}

Já escrevemos que Sartre, no seu último ano de vida, escolheu como destino da sua "(pen)última viagem" justamente a sua amada cidade de Veneza ${ }^{21}$. Ora, se isto não um argumento definitivo nem comprobatório, ao menos ilustra com muita precisão o seu amor pela Itália, e, em especial, por esta cidade. Mas esta devoção às cidades da Itália já era bastante conhecido pelo público francês, e é isto que a fórmula de BernardHenri Lévy resume: "(...) Sartre, simplesmente, passa seu tempo na Itália; ele é, desde Stendhal, o escritor francês que mais profundamente foi italiano; (...)." 22 É neste sentido que se pode afirmar que, de alguma maneira, o texto La reine Albermale ou le dernier touriste pode ser compreendido como as Crônicas Italianas de Sartre; mas é claro que devemos ter sempre em mente que mais de um século separam estes dois livros: não se viajou no século XIX da maneira como se viajou no século passado. No entanto, quando Stendhal escreveu as suas crônicas viáticas já existia tanto a figura do turista quanto o próprio termo, e não devemos esquecer que ele mesmo já tinha colocado, em um dos seus livros, o título Memórias de um turista... Foi abordada esta questão porque uma considerável parte dos textos em fragmentos do supracitado livro de Sartre é, por um lado, a narrativa de uma personagem cuja condição de turista é auto-proclamada, e, por outro lado, pode ser compreendida como uma espécie de manifesto contra os turistas e o turismo de massa. Ao considerar, neste texto escrito no ano de 1951, a economia italiana, é sem maiores escrúpulos que o filósofo francês afirma: "(...) o problema nº 1 para o italiano é o de salvar a sua indústria nacional, o turismo."23 Isto significa que a Sartre não escapava o inelutável destino de muitos países e de inúmeras cidades, o de serem visitadas por algum turista apressado (sempre apressado, os guias locais e as agências as urgências de turismo - ditam o ritmo) e serem reproduzidas como imagem icônica na cultura de massa. Mais adiante, o nosso autor confirma este fa(r)do: "Trata-se de vender o passado por dólares a pessoas que estão pouco ligando para o passado." 24 E a quem se referia o filósofo francês? Isto é, quem seria este hipotético viajante desinteressado em relação ao passado? Como o 
continuação da nota 13. schéma de représentations mentales et culturelles qui nous empêchent de découvrir ce qui se présente à la vue. Dans l'indien du Nouveau Monde, Colomb voit I'Homme d'Eden, le mythe du bon sauvage c'est-à-dire notre alter ego de la Gênese" (2001, p. 8)

14 Acerca desta última niaiserie Requemora faz uma observação curiosa: "Literariamente, é, no entanto, a Turquia que simboliza nominalmente todos os países orientais. A moda das 'turqueries' é assim mais geralmente oriental que propriamente turca" (2002, p. 255). Tradução nossa do Francês para o Português. No original lê-se: "Littérairement, c'est néanmoins la Turquie qui symbolise nominalement tous les pays orientaux. La mode des "turqueries" est ainsi plus généralement orientale que proprement turque" Ou seja, o Oriente era percebido vagamente e compreendido desde o termo "genérico" de "Turquia". Isto mostra claramente que não apenas os homens e os modos são estereotipados, mas o próprio espaço.

15 Teremos a oportunidade de tratar, mais adiante, da personagem tão difamada que é o "turista de massa", aquele que parte em grandes comboios.

16 Le Larousse. Paris: Larousse, 1998.

17 Plutarco nos apresenta uma boa definição desta prática política: "Esta maneira de banir, a que chamavam de Ostracismo ou Oxtracismo, não era um castigo imposto por qualquer crime ou malfeitoria. Segundo diziam, o que visavam era apenas dar uma capa honesta aos atingidos para abater uma autoridade e um poder excessivos, incompatíveis em um estado popular. Na verdade, porém, não passava de um meio pelo qual se procurava contentar graciosamente povo, quando este concebia inveja contra alguém que se encontrava em autoridade e evidência, constrangendo-o a abster-se de qualquer atividade pública, pelo prazo de dez anos. Entretanto, quando começaram a aplicar tal pena a pessoas sem representação ...continua na próxima página leitor já terá adivinhado, a referência implícita está diretamente relacionada aos cidadãos do país que ele havia visitado nos anos de 1945 e 1946 e cuja viagem havia sido cercada de tantas expectativas: os norte-americanos.

É curioso observar como os cidadãos deste país estão geralmente associados a um turismo banal. Marguerite Yourcenar, no livro já citado neste artigo, indigna-se com "turistas americanos do Tenessee" (o "Tenessee" da frase vem reforçar a vulgaridade da cena a ser narrada) que teria encontrado no Cairo, e que jamais se davam a oportunidade de conhecer realmente o país visitado. Dormindo em hotéis para norte-americanos, se alimentando à maneira norte-americana, vendo arranha-céus como os do seu país, não têm uma verdadeira experiência viática, a qual a autora belga define nestes termos: "Ver bem um país é tentar conhecê-lo e até certo ponto torná-lo seu em seu presente e seu passado, buscar ver, enfim, o que ele significa para os que ali vivem" (1992, p. 122). A arquitetura, que já definimos alhures como um importante ponto desta experiência, se reduz a "uma série de grandes bibelôs arquitetônicos", contemplados rapidamente e rapidamente esquecidos. Poder-se-ia imaginar e escrever sobre o bric-à-brac das memórias de um "turista de massa", nas quais catedrais góticas "endomingadas" se fundem - ou se confundem, o que neste caso dá no mesmo - com pirâmides egípcias iluminadas por holofotes, e estas, por sua vez, com as pirâmides contemporâneas de Las Vegas. Esta memória faz pensar na divisa que, segundo Sartre, seria a do turista: "Ao novo o antigo preferirás, e ao antigo o seu antigo estado de novo." 25

Mas se escreve sobre Sartre e o amor devotado por ele a Itália; todavia, antes de retornar a este ponto, permitir-se-á reportar as suas críticas aos turistas norte-americanos, posto que ele também tinha os seus "turistas do Tenessee" para deplorar, os quais eram, aliás, marinheiros:

Os marinheiros têm olhares de lã, eles acham que Roma é um grande vilarejo mexicano e que as ruínas, no meio da praça, são insólitas; os romanos têm olhares de ave, eles acham que os marinheiros, no meio das ruínas, são insólitos. Os marinheiros pensam em suas mães, belas senhoras que dançam nos seus aniversários; para ser venerável, é necessário que se assemelhe a um objeto de arte: que seja antigo mas que ainda tenha um uso. Uma igreja é perfeita: ali se reza a missa. Mas um templo? Os romanos pensam que a cultura está em vias de morrer. ${ }^{26}$

Os turistas norte-americanos, estes algozes cruéis da bien aimée cultura clássica italiana... Ora, haveria uma motivação subjacente a este comentário tão pouco complacente do filósofo francês? É certo que tanto no caso de Yourcenar quanto no de Sartre há um certo quê de snobismo de um intelectual europeu face à pretensa ignorância e pouca sofisticação espiritual destes "selvagens do Novo Mundo". Além disto, não se estaria longe da verdade e não se infringiria nenhuma convenção social se se afirmasse que o filósofo francês estaria, ao analisar o comportamento dos marinheiros norte-americanos, e aos thes emprestar sensações e pensamentos, colocando um aprendizado em prática: o pouco prestígio que, segundo ele, o passado gozaria nos Estados Unidos da América. De alguma maneira, os marinheiros estariam encenando uma peça cujo roteiro Sartre já conhecia de antemão, apenas, em relação as suas duas viagens aos Estados Unidos da América, o décord havia mudado: eles não estavam mais em casa - mas ainda pensariam nas suas mães.. -, e sim em um país estrangeiro do qual teriam ouvido falar de maneira um tanto vaga e genérica. Por outro lado, não se deve esquecer que a representação que Sartre fez dos marinheiros corresponde, na realidade, a um estereótipo, os tais "turistas do Tenessee": apressados, "broncos" e incapazes de compreender uma realidade que não seja estritamente prática: como as suas ruas retas, as suas cidades provisórias e as suas casas desmontáveis... WAo que parece, os Estados Unidos da América já haviam se tornado uma espécie de antimodelo - e mesmo um anti-modelo urbano - para o filósofo francês; a referência realizada acima ao urbanismo dos Estados Unidos da América encontra a sua justificativa no fato de que a descrição feita em meados dos anos 1940 foi convocada, em 1951, para "prestar contas":

Ah! Eu sei bem o que é necessário fazer, o que eles [os italianos] acabarão por fazer, o que eles já começaram: reconstruir uma bela cidade leve e nova, americana, com ruas retas, com parques; não conservar nos squares bem floridos senão o 
continuação da nota 17 .

social e também a indivíduos maus, como se deu com um de nome Hipérbolo, que foi o último a ser expulso, seu uso foi inteiramente abandonado em Atenas" (s/d, V. 3, p. 331). Tradução do Francês para o Português por José Carlos Chaves.

18 Les lieux de Marguerite Duras. Paris: Les éditions de minuit, 1977. Tradução nossa do Francês para o Português. No original lê-se: "Elle avait peur de cette étrangété-là, ces tropique qu'elle découvrait tard dans as vie" (p. 26).

19 Tradução nossa do Francês para o Português. No original lê-se: "Ce guide exprime le code pittoresque anglais en vigueur depuis les voyages de Gilpin au XVIIle. Siècle. Dès la première phrase, on retrouve le vocabulaire chère aux romantiques avec l'emploi de l'adjectif 'pittoresque'" ilmaginaire français en Amérique du Nord: genèse d'un tourisme de distinction à Québec et la Nouvelles-Orléans: note de recherche. In: Anthropologie et sociétés, vol. $25, n^{\circ} 2$, 2001, p. 152.

20 No que se refere a França, há uma data paradigmática que inaugura uma nova possibilidade para as classes populares, como na fórmula de Prelorenzo e Picon: "Para a França, é '36', dois números, uma data que ressoa como um programa, um futuro e uma revanche" (1999, p. 09). Os autores se referem à instituição das férias pagas, que transformou operários e pequenos funcionários em turistas. Contudo, para este autor, o turismo na Europa teria se massificado apenas nos anos 1960, quando as condições de hospedagem e de transporte teriam se tornado mais acessíveis (1999, p. 12).

21 Sartre esteve na Itália pela primeira vez no ano de 1933 , aproveitando-se de um generoso "desconto fascista"; é Beauvoir quem nos conta: "Naquele ano, Mussolini organizara em Roma uma 'exposição fascista' e, para atrair os turistas estrangeiros, as estradas de ferro italianas concediam uma redução de $70 \%$. Aproveitamos sem escrúpulo." In: Beauvoir, Simone de. A força da idade. Trad.: Sérgio Millet. Rio de ...continua na próxima página essencial, alguns monumentos-testemunhos, uma amostra bem feita. ${ }^{27}$

Desta vez, não há nenhuma simpatia e nem sequer indulgência em relação às cidades norte-americanas; o que nos dois textos viáticos anteriores poderia ser compreendido como desdém ou condescendência de um superior face a um inferior se tornou, simplesmente, objeto de ironia: italianos, tornemse "americanos", esqueçam o passado, reformem as suas cidades segundo o espírito do capitalismo industrial, e, finalmente, tudo entreguem a estes "turistas". É, parece que Sartre não amava mais New-York (e nem a nova-iorquina que, segundo ele, lhe teria entregue a "América": Dolorès vanetti...).

Permitir-se-á, ainda em relação à cena dos marinheiros norte-americanos diante do pórtico do Panteão, uma observação suplementar. O texto em questão foi escrito em 1951, e os soldados norteamericanos ainda representavam, no imaginário dos intelectuais de esquerda europeus, aqueles que haviam lutado pelo chamado "mundo livre", derrotando, então, o fascismo. Porém, cedo esta imagem seria substituída pela cena dos aviões militares norte-americanos lançando bombas de nalpam sobre os vietnamitas - mas, em 1951, o Sartre político teria que se preocupar com a Indochina, e não com o Vietnam..

Mas deixemos em paz os marinheiros norteamericanos e retornemos a nossa tarefa, isto é, escrever sobre a relação do filósofo francês com a Itália. Todavia, ainda caberia uma pequena observação sobre os turistas na Itália, tal como Sartre os descreveu. Com isto, parece que se distancia do tema principal, mas não se pode ser acusado desta "perda de tempo" que é a digressão (no sentido de se distanciar), uma vez que o turismo pode ser considerado um tema central neste livro de Sartre. E exibir-se-á uma passagem de caráter anedótico que demonstra o quão a personagem era intransigente em relação ao turismo de massa: "Afastar as sete colinas e as numerar: eu vi australianos que queriam ser reembolsados porque só haviam visto seis delas. " 28 As vítimas da ironia mordaz de Sartre, desta vez, foram os australianos, anglo-saxões como os norteamericanos e, ainda por cima, parbleu! são do "Novíssimo Mundo"... Impossível ser mais parvenu.
Espectador de uma encenação no Coliseu, no qual turistas pagaram para se fantasiar de respeitados cidadãos da Roma Antiga (os italianos pobres, por sua vez, morriam em 800 liras para se fantasiar de mártires), parece que a este personagem comprazia o deleite mórbido de negar um estatuto mais digno a sua condição de turista: "Preso em flagrante delito de turismo: no anfiteatro Flaviano não se devoravam os homens, matava-se a besta". ${ }^{29} \mathrm{O}$ turismo, se não é um crime, parece ser, ao menos, uma contravenção, um atentado ao pudor, uma ode ao mau gosto ou uma impostura: "É preciso ser italiano para poder ter inventado de colocar os turistas na arena". 30 Ou, talvez, norte-americanos, mas estes não têm ruínas - e, segundo Sartre, nem monumentos...

Feitas estas considerações, sobre turismo e turistas, sempre sob a ótica da personagem criada por Sartre, vamos, então, a tarefa primordial deste artigo, a relação deste com a Itália. Mas, antes, a paciência do leitor terá que permitir um tema paralelo: o conhecimento que o filósofo francês possuía da arquitetura. Apesar deste ter sido declarado como "paralelo", este tema não é irrelevante na nossa exposição, uma vez que se está analisando, justamente, textos sobre cidades e arquitetura produzidos por um filósofo que pouco escreveu sobre isto. Neste sentido, os textos mais elucidativos não são, todavia, aqueles os quais já foram objeto de estudo de um artigo anterior, mas aquele sobre o qual, neste sub-capítulo, se está analisando. Isto já demonstra que Sartre sentia-se mais "em casa" diante da arquitetura clássica da Itália do que face aos fenômenos urbanos norteamericanos e os seus arranha-céus. Isto, contudo, já foi afirmado, falta, agora, prová-lo. Vamos às evidências, então:

A fachada da Piazzeta é bela porque ela não pesa e porque ela se eleva. É esta luta contra o peso que faz a sua força. Reprovavam-na, no tempo de Ruskin, o fato das suas arcadas serem muito baixas. Mas é necessário. É ela que marca a loggia [enfoncement no original]. Altas e leves, elas nos dariam a impressão que o palácio seria fácil de ser sustentado. No lugar disto, elas nos fazem sentir um ser carregado que não se dobra, mas que afunda a cada passo na terra. (...) No fundo eu direi mesmo que se trapaceia um pouco, porque ele [o palácio] parece mais pesado do que é. ${ }^{31}$ 
continuação da nota 21 ...

Janeiro: Nova Fronteira, 1984, p. 156. Como se pode observar, para intelectuais pobres desconto não tem ideologia, mas depois, quando se é uma instituição, pode-se recusar com conforto até milhões de coroas suecas.

22 Lévy, Bernard-Henri. O século de Sartre. Trad.: Jorge Bastos. Rio de Janeiro: Nova Fronteira, 2000, p. 398

23 Tradução nossa do Francês para o Português. No original lê-se: "(...) le problème $n^{\circ}$. 1 pour l'Italien, c'est de sauver son industrie nationale, le tourisme" (1991, p. 41).

24 Tradução nossa do Francês para o Português. No original lê-se: "Il s'agit de vendre du passe contre des dollars à des gents qui se foute du passé" (1991, p. 41)

25 Tradução nossa do Francês para o Português. No original lê-se: "Au neuf I'ancien préféreras et à l'ancien son ancien état de neuf" (1991, p. 50).

26 Tradução nossa do Francês para o Português. No original lê-se: "Les marins ont des yeux en laine, ils trouvent que Rome est un grand village mexicain et que ces ruines sont insolite aux mileieux de la place ; les Romains ont des yeux d'oiseaux, ils trouvent que ces marins sont insolites au milieux des ruines. Les marins pensent à leurs mères, belles vieilles qui dansent aux anniversaires ; pour être vénérable, il faut qu'un objet d'art leur ressemble: qu'il date mais qu'il fasse encore de l'usage. Une église, c'est parfait : on y dit la messe. Mais un temple? Les Romains pensent que la culture este n trains de mourir" (1991, p. 41).

27 Tradução nossa do Francês para o Português. No original lê-se: "Ah! Je sais bien, moi, ce qu'il faut faire, ce qu'il finiront bien par faire, ce qu'ils ont déjà commencé : reconstruire une belle ville légère et neuve, américaine, aux rues droites, avec des parcs; ne garder dans les sqaures bien fleuris que l'essenciel, quelques monuments témoins, un échantillage bien fait" (1991, p. 42).
Estas análises de Sartre são bem distintas daquelas que ele empreendeu a respeito da arquitetura e das cidades norte-americanas - em 1945 ele escrevia motivado pelo espanto diante de uma paisagem estrangeira, aqui a sua apreensão é a de um esteta a quem a arquitetura não deixa indiferente. Além disto, pelas frases emprestadas a sua personagem, um turista francês na Itália, ele parece conhecer o vocabulário da arquitetura e sentir-se seguro o suficiente para emitir as suas próprias opiniões sobre este domínio artístico: "A arquitetura são linhas. Mas isto não significa minimamente que a pedra deve ter muitas curvas." 32 E isto implica, ainda, a preferência por uma forma de arquitetura em detrimento de outras:

As fachadas (1404 - e talvez até 1365 - e outra 1424-1457). Todo o resto, com exceção do Arco Foscari, a fachada oriental que é do século XVI, e as fachadas meridional e ocidental que são do século do século XVII, é entediante, barroco e frio. Sempre o mesmo erro: no fundo o belo em arquitetura, disciplina retirada do útil, é que a pedra esteja em movimento. Nada além disto. Por quê? Porque se trata de conferir a unidade de uma transcendência humana àquilo que é, de fato, a pura queda da inércia espacial. ${ }^{33}$

Não se trata da análise de um "especialista" em arquitetura ou de um profissional, mas de um intelectual que conhecia os fundamentos desta disciplina. Mas este fato não deve causar espanto, uma vez que, se no Brasil o conhecimento em arquitetura quase sempre foi um "nicho" de profissionais, na Europa é uma espécie de "pano de fundo cultural" de uma formação nas Humanidades, junto com a alta literatura, a música erudita e a pintura. Bacon, ao preconizar a viagem como o modo de conhecimento da arquitetura e das cidades, concordaria com esta asserção, Sartre e outros tantos intelectuais a confirmariam. É Beauvoir quem nos relata o encontro de Sartre com a arquitetura grega clássica, fato que corrobora as afirmações acima: “Em Pesto contemplamos pela primeira vez um templo grego. Sartre ficou desnorteado, pois me disse: 'Não há o que pensar disto'" (1984, 271). E, mais adiante: "Em Segesta começamos a sentir o que significava uma coluna dórica" (1984, 273). E, ainda: "Não ficávamos mais tomados de mutismo em face dos templos gregos; tínhamos aprendido a traduzi-los em palavras; na Pnice evocávamos os séculos passados, as assembléias, as multidões, os rumores da Antiga Atenas" (1984, 304). É claro que há muito de código literário e mesmo de convenção social nas palavras quase românticas de Beauvoir, posto que a frase "o templo grego me deixou completamente indiferente" não poderia ser escrita por intelectuais, a não ser, naturalmente, com a explícita intenção de chocar o leitor. Mais uma vez, ao se fazer literatura e ao se escrever sobre viagens, repete-se um certo padrão literário: antes deste encontro de Sartre e Beauvoir com a arquitetura clássica grega já não tinha existido Lord Byron e tantos outros grandes viajantes?

É pensando nesta questão que foi narrada a viagem do casal de intelectuais a Grécia; ora, se eles apreciavam a arquitetura clássica, se se emocionavam e tinham fruição estética é porque isto já fazia parte da sua formação. E é mister afirmar, para concluir o tema, que a este filósofo não interessava nem a arquitetura da sua época nem a questão do urbano como objeto de reflexão. Se no final dos anos 1960 Guy Débord já se insurgia contra o modelo de urbanismo, e se Henri Lefebvre fazia do urbano um dos temas mais importantes do seu pensamento, a Sartre estas questões eram indiferentes. Isto significa, se o leitor nos conceder o privilégio do consentimento, que tanto nos Estados Unidos da América quanto na Itália a arquitetura e as cidades surgem e são tratados a partir da perspectiva literária do inventário realizado por um viajante.

Esclarecida esta questão, voltar-se-á, então, às relações entre a Itália e o filósofo francês. Já se escreveu sobre a condição do seu amor devotado à cidade de New-York, um sentimento quase condescendente, de um amante que, secretamente, sente um certo desdém pelo objeto que deveria amar; já em relação a Veneza, o amor ousa pronunciar o seu nome:

Eu escutei uma mulata que falava de uma certa espécie de tristeza reprimida, muito levemente ansiosa e doce, cheia com ele mesma, e para explicar ela dizia: "Como quando fez-se muito amor sem amizade." Eis: eu amo Veneza, mas sem sentir amizade. ${ }^{34}$

Sartre não se referia a um sentimento sereno e já cotidiano, mas a uma experiência afetiva e a 
28 Tradução nossa do Francês para o Português. No original lê-se: "Bien dégager les sept collines et les numéroter j'ai vu des Australiens qui voulaient faire rembourser pour n'en avoir vu que six" (1991, p. 42).

29 Tradução nossa do Francês para o Português. No original lê-se: "Pris en flagrant de tourisme: dans l'anphithéatre Flavien on ne bouffait pas I'homme, on tuait la bête" (1991, p. 49).

30 Tradução nossa do Francês para o Português. No original lê-se: "Il faut être Italien pour avoir inventé de parquer les touristes dans l'arène (1991, p. 48).

31 Tradução nossa do Francês para o Português. No original lê-se: "La façade de la Piazzetta est belle parce qu'elle pèse et parce qu'elle s'élève. C'est cette lutte contre la pésanteur qui fait sa force. On lui reprochait, du temps de Ruskin, que les colonnes des arcades soient trop basses. Mais il le faut. C'est qu'elles marquent I'enfoncement. Hautes et légères, elles nous auraient dit que les palais est facile à porter. Au lieux qu'elles nous font sentir un être charge que ne plie pas mais qui s'enfonce à chaque pas dans la terre. (...) Dans le fond je dirait même qu'on truque un peu, on le fait plus lourd qu'il n'est" (1991, p. 129).

32 Tradução nossa do Francês para o Português. No original lê-se: "L'architecture ce sont des lignes. Mais cela ne signifique point que la pierre doive avoir beaucoup de courbes" (1991, p. 129)

33 Tradução nossa do Francês para o Português. No original lê-se: "Les façades (1404 - et peut-être même 1365 - et I'autre 1424-1457). Tout le reste sauf I'Arc Foscari, la façade orientale qui est du XVle., et les façades méridionale et occidentale qui sont du XVIle., est ennuyeux, baroque et froid. Toujours la même erreur : dans le fond le beaux en architecture, jailli de l'utile, c'est que la pierre soit en mouvement. Rien que cela. Pourquoi? Parce qu'il s'agit de donner l'unité d'une transcendence humaine à ce qui est en fait pure retombé de l'inercie spatiale" (1991, p. 129). uma relação carnal que poderia, inclusive, ser perturbadora. É certo que não se trata de comparar os dois textos viáticos sobre os Estados Unidos da América, Villes d'Amérique e New-York ville coloniale, nos quais as observações eram emitidas pelo próprio autor, com La reine Albermale ou le dernier touriste, no qual as afirmações são de responsabilidade de uma personagem, nomeado apenas como "turista". Pretendeu-se, simplesmente, apoiar a reiterada afirmação, aliás, já bastante conhecida, de que Sartre preferia Veneza às cidades norte-americanas que conheceu nos anos de 1945 e 1946.

Ainda a respeito deste ponto, é importante reconhecer que talvez seja impossível - e, de resto, inútil - perceber até que ponto a aversão de Sartre à política dos governos norte-americanos teria pesado no seu sentimento pelas cidades deste país. New-York é citada no texto de 1951 cinco vezes - e quase sempre como uma espécie de contra-ponto às cidades européias - , e a personagem, no entanto, abstém-se emitir juízos de valor, como se aquela realidade urbana não Ihe dissesse mais respeito, e, a este título, não lhe interessasse mais. Esquece-se New-York, como se esquecem os relacionamentos de ocasião e os fatos sem importância.

\section{Últimas considerações acerca do último turista}

Para concluir este artigo, acrescentaremos mais uma observação de Sartre sobre o turismo e os turistas - na medida mesmo que esta é elucidativa em relação ao que foi já foi exposto aqui - e que não havia ainda sido tratado diretamente e nem sequer nomeado, e que o será por esta palavra: paradoxo. É paradoxal que alguém para quem as viagens tenham tido tanta importância, e que tenha mesmo criado uma "personagem turista", pareça ter tanto desprezo pelas experiências que acompanham, inevitavelmente, um turista, e todo e qualquer turista: é inevitável visitar construções alçadas à condição de monumentos históricos, como os aludidos no texto de Sartre; novamente inevitável é encontrar turistas para quem a experiência viática é como qualquer outra, assim como são incontornáveis os espetáculos banais e as falsas experiências viáticas... "A morte, o esquecimento, o irremediável, as dores do amor perdido, as ocasiões desperdiçadas, eis os alimentos cotidianos do turista. (...) O turismo é uma flor do Mal." Não podia ser mais pessimista... É a doutrina segundo a qual só estariam interessados em viajar aqueles para quem os dissabores da vida são inconsoláveis, e que, ainda assim, procuram consolo na distância, na errância, na perpétua mudança de ares, de planos e de paisagens. O otimista, ainda segundo Sartre, não viaja, e não o faz por princípio:

Mas se você acredita que o vinho de Bordeaux é melhor hoje que em 1780 e que, de resto, não havia fechamento nem appelation contrôlée naquela época, se você acredita que pode desfrutar de todos os prazeres que eles desfrutavam [os avôs] e que eles não podiam usar o avião, então, você achará errado o comércio da Itália. ${ }^{35}$

O filósofo francês referia-se ao "comércio" das ruínas, das esculturas e dos monumentos; referia-se - novamente... - aos turistas norte-americanos que perambulariam pelas ruínas italianas atrás de modelos para ornar as suas residências de campo: esculturas de anjos, de deuses pagãos e colunas, muitas colunas. Mas não se deve dizer-Ihes que não se constrói uma ruína, ainda segundo o filósofo francês, eles devem acreditar que estas são o fruto de uma próspera indústria... Aquele que acredita no progresso - o otimista - não viajaria a Itália. Ora, seria este "turista" o "último" da sua espécie justamente porque estaria consciente da sua maldição? Como ter uma experiência "genuína" com o outro se o outro - a cultura estrangeira e o próprio estrangeiro: os romanos diante dos norte-americanos, e estes diante do Panteão - é, por definição, aquele - e aquilo - que não se é? Por outro lado, a busca, por parte de um turista, de algo que poderia ser definido como uma "autêntica experiência viática" - pensemos, a este respeito, em Yourcenar -, que corresponderia a uma "autêntica experiência com o outro", esbarra na simples complexidade do próprio conceito de autenticidade. Ora, por que um por do sol na Toscana seria mais "autêntico" que um Coliseu apinhado de turistas? Yourcenar aviou-nos a receita do conhecimento de um país estrangeiro, mas o seu otimismo pouco nos serviria para compreender as motivações do turista criado por Sartre.

O paradoxo é evidente, mas se deve esclarecer, 
34Tradução nossa do Francês para o Português. No original lê-se: "J'ai entendu une mulâtresse qui parlait d'une certaine espèce de tristesse repue, très légerment anxieuse et douce, bornée à elle même, et pour l'expliquer elle disait : 'Comme lorqu'on a trop fait l'amour sans amitié' Voilà : j'aime Venise mais sans amitié" (1991, p. 90).

35 Tradução nossa do Francês para o Português. No original lê-se: "Mais si vous croyes que le vin de Bordeaux est meilleur aujourd'hui qu'en 1780 et qu'au reste à cette époque il n'y avait pas de clos ni d'appellation crontrôlée, si vous croyer que je peux jouir de tous les goûts dsont ils jouissaient et qu'eux nepouvaint pas monter en avion, alors vous porter tort auc commerce italien" (1991, p. 44)

36 Mas Sartre, é claro, jamais foi conhecido por ser um virtuose da escritura: "Ele não relê os seus manuscritos. Mal corrige as provas. Nunca verifica a exatidão, ou a origem, de uma citação. Deixa passarem incorreções, fraquezas, redundâncias, que uma simples releitura haveria detectado e das quais se dá conta após a publicação" (2000, p. 248). A frase é de Bernard Henri-Lévy, que complementa: "Ou seja, poderia ter dito que livro algum seu foi terminado, havendo aí, no coração do programa, uma estranha compulsão que é só dele" (2000, p. 250).

37 Emprestamos esta expressão de Henri-Lévy (2000, P. 274).

38 Henri-Levy conclui que este pessimismo é da ordem do trágico: "Se foi estabelecido chamar de 'trágica' a visão de um mundo em que contrários não se conciliam, se 'trágico' designa essa visão não dialética das diferenças, será preciso dizer que o primeiro Sartre é um pensador do Trágico" (2000, p. 280). ainda, dois pontos. Eis o primeiro: este conjunto de fragmentos de textos jamais foi concluído, e não podemos tratá-lo como uma obra acabada e refletida, a qual o autor teria tido tempo e vontade para, digamos, lapidá-la, e, neste sentido, não se pode conceder-lhe o mesmo estatuto do restante da obra de Sartre, como os dois textos já analisados por nós ${ }^{36}$. O segundo ponto que seria importante esclarecer é externo à obra: Sartre era conhecido por sua intransigência e por seu "gosto pela querela" ${ }^{37}$, mas o pessimismo ${ }^{38} \mathrm{em}$ relação às viagens de um grande viajante talvez seja um sintoma nada desprezível de uma doença talvez incurável. No ano em que os textos foram escritos, a Europa ainda sentia o esmagador peso - econômico e, igualmente, moral, pelo menos no que se refere a Itália, a França e a Alemanha - da Segunda Guerra Mundial, e talvez o filósofo francês tenha-nos escrito sob este signo e neste espírito: os marinheiros norte-americanos, diante do Panteão, como bárbaros de outrora em um império arruinado.

\section{Referências bibliográficas}

Beauvoir, Simone de. A força da idade. Trad.: Sérgio Millet. Rio de Janeiro: Nova Fronteira, 1984

---. A cerimônia do adeus. Trad.: Rita Braga. Rio de Janeiro: Nova Fronteira, 1984.

Boutier, Jean. Le Grand Tour: une pratique d'éducation des noblesses européenes (XVIe.-XVIIle.). Em: Babel, Rainer e Paravicini, Werner (Orgs.). "Grand Tour. Adeliges Reisem um europäische Kultur von 14 bis zum 18. Jahrhundert." Akten der internationalen Kolloquien in der villa Vigoni 1999 um im Deutschen Historischen Institut Paris 2000, "Beihefte der Francia", 60, Ostfildern, Jan Thorbecke Verlag, p. 237-253.

Corbin, Alain. O território do vazio - a praia e o imaginário ocidental. São Paulo: Companhia das letras, 1989.

Fernandez, Bernard. L'homme et le voyage, une connaissance éprouvée sous le signe de la encontre. Em: Barbier, R. (Org.). Education et sagesse: la quête du sens. Paris: Albin Michel, 2001.

Geronimi, Martini. Imaginaire français em Amérique du
Nord: gênese d'un tourisme de distinction à Québec et la Nouvelle-Orléans: notes de recherche. Em: Anthrpologie et Sociétés, vol. 25, n², 2001, p. 151166. URL: http//id.erudit.org/iderudit/00239ar.

Guennoc, Jean-François. Le voyage en son siècle: réflexions sur le rapport entre le voyage et l'histoire culturelle. Em: Revue CRLV.org, nº. 2, maio 2006. URL: http://www.crlv.paris4.sorbonne.fr/ revue_crlv?article $=7$

Lévy, Bernard-Henry. O século de Sartre. Trad.: Jorge Bastos. Rio de Janeiro: Nova Fronteira, 2000.

Lima, Adson Cristiano Bozzi Ramatis Lima. Sartre na América ou memórias de um "bourgeois épaté. In: Cadernos de Arquitetura e Urbanismo PUC-Minas,v. 13, 2006.

---. Imago Mundi: a escritura do mundo - as cidades norte-americanas sob o olhar de Jean-Paul Sartre. In: Revista Risco, v. 7/1, 2008

Prélorenzo, Claude; Picon. L'aventure du balnéaire, Paris: Parenthèses, 1999.

Requemora, Sylvie. L'espace dans la littérature de voyages. Em: Etudes Littéraires, v. 34, n. 1-2, 2002, p. 249-276. URL: http//id.erudit.org/ iderudit/0075666ar

Sartre, Jean-Paul. La reine Albermale ou le dernier touriste. Paris: Gallimard, 1991

---. Villes d'Amérique; New York, ville coloniale; Venise de ma fenêtre. Paris: Editons du patrimoine, 2002.

Yourcenar, Marguerite. A volta da prisão. Rio de Janeiro: Martins Fontes, 1999. 


\title{
Abstracts / Resumenes
}

\section{Urbi et Orbi - Jean-Paul Sartre in italian cities or the last memories of a tourist}

Adson Cristiano Bozzi Ramatis Lima

\begin{abstract}
The French philosopher Jean-Paul Sartre established a relationship of great affection with Italy and its cities, especially Rome and Venice. And on this issue, has left at least one large urban privileged witness of this relationship, the book unfinished and published posthumously with the title La reine Albermale ou le dernier touriste. This article has tree main objectives: first to explain the relationship of Sartre to the Italian cities and their architecture, and show how mass tourism can be understood on a pejorative way by European intellectuals and directly related to the Americans; and finally, explain the importance critic of the récit de voyage.
\end{abstract}

Keywords: Jean-Paul Sartre, tourism, Italy.

\section{Urbi et Orbi - Jean-Paul Sartre en las ciudades italianas o los últimos recuerdos de un turista}

Adson Cristiano Bozzi Ramatis Lima

\section{Resumen}

El filósofo francés Jean-Paul Sartre tiene una relación de gran cordialidad con Italia y sus ciudades, y entre ellos, sobre todo en Roma y Venecia. Y acerca de esta relación privilegiada urbana, La reina le dernier touriste o Albemarle (el título del libro inacabado y publicado póstumamente) es uno de los testigos principales. Este artículo tiene tres objetivos principales, es decir, exponer la relación de Sartre a las ciudades italianas y su arquitectura, mostar como el turismo de masas puede ser entendido de una manera peyorativa, y, finalmente, exponer la importancia y la fortuna crítica de la narrativa de viajes.

Palabras clave: Jean-Paul Sartre, turismo, Italia. 